\title{
A Study of Nerve Conduction Test \& Other Hematological Parameters in Diabetics
}

\author{
Jasmin J. Parmar' ${ }^{1}$ Jitendra R. Patel ${ }^{2}$ \\ ${ }^{1}$ Associate Professor, Department of Physiology, Banas Medical College \& Research Institute, Palanpur, Gujarat, \\ ${ }^{2}$ Associate Professor, Department of Physiology, Gujarat Adani Institute Of Medical Science, Bhuj, Gujarat
}

\begin{abstract}
Background: Nerve conduction studies (NCS) are most sensitive, reliable and non-invasive investigation to detect diabetic neuropathy. Sensory nerves are more affected as compared to motor nerves in diabetic neuropathy. Understanding the Nerve conduction studies is useful for early detection polyneuropathy and prevention of its dreaded complications.

Materials and Method: The present study was conducted among 30 subjects of type 2 Diabetic and 30 non diabetics subjects. Haematological parameters such as $\mathrm{HbA1c}$, platelet count, prothrombin time, APTT, triglycerides, LDL and HDL levels were estimated. Motor nerve conduction velocity median , ulnar, common peroneal and posterior tibial nerve and sensory nerve conduction velocity median, ulnar and sural nerve were recorded.
\end{abstract}

Result: Mean age of diabetic patients was $51 \pm .4 .8$ year. Most of the subjects ( $86.7 \%)$ were male. Sensory nerve conduction of sural nerve was signiicantly reduced in diabetic patients as compared to non diabetic patients. SNCV of sural nerve showed deterioration with the duration of diabetes, poor glycemic control and patients with altered lipid profile.

Conclusion: Nerve conduction velocity testing of sural nerve is useful for early detection of diabetic neuropathy and reduce the burden of complication and to improve the quality of life in diabetics.

Keywords: Sensory nerve conduction velocity, Sural nerve, Diabetic peripheral neuropathy, HbAlc

\section{Introduction}

Diabetes mellitus (DM) is a metabolic disorder characterized by chronic hyperglycaemia with abnormalities in carbohydrate metabolism. ${ }^{1}$ In India, prevalence of diabetic peripheral neuropathy in Type 2 diabetic patients was $26.1 \% .^{2}$ Distal symmetric sensorimotor polyneuropathy is the most common clinical type of DPN. Three fourth of neurologically asymptomatic patients may have abnormal nerve conduction. ${ }^{1}$ Age, male gender, duration of diabetes, glycated hemoglobin levels and insulin use increase risk of peripheral neuropathy . $^{3}$

\section{Corresponding Author:}

\section{Dr. Jitendra R. Patel}

Associate Professor, Department Of Physiology, Gujarat Adani Institute Of Medical Science, Bhuj, Gujarat
Nerve conduction studies (NCS) are most sensitive, specific, reliable and non-invasive investigation to detect diabetic neuropathy. ${ }^{4}$ Routine NCS include evaluation of motor conduction velocity of the median, ulnar, peroneal and tibial nerves, and sensory conduction velocity of median, ulnar and sural nerves. ${ }^{1}$ Sensory nerves are more affected as compared to motor nerves in diabetic neuropathy. ${ }^{5,6}$ Relationship between poor glycaemic control and DPN has been reported by various authors. ${ }^{7,8}$ The Nerve conduction studies (NCS) is crucial for early detection and prevention of its dreaded complications of DPN. ${ }^{9,10}$

\section{Aims \& Objectives}

$>$ To study nerve conduction velocity in type 2 diabetes mellitus patients and non diabetic patients.

$>$ To study corealtion of haematological parameter 
like HbA1c, platelet count, prothrombin time, APTT, triglycerides, LDL and HDL levels with development of polyneuropathy.

\section{Materials and Method}

The present study was conducted among 30 subjects of type 2 Diabetic Subjects in age group (30-65 years) attending out patient clinic of Nalini Chowdhary's neuro center in Hanamkonda, Telangana. The another 30 patients of age group of 30-65 years who seeking for various other medical problems without diabetes were included in control group. Patients with neuropathy due to any other cause were excluded. Detail history regarding complaints of neuropathy was taken. Haematological parameters such as $\mathrm{HbAlc}$, platelet count, prothrombin time, APTT, triglycerides, LDL and HDL levels were estimated in diagnostic center at Hanamkonda.

Nerve conduction studies were performed with Clarity Octopus NCV/EMG machine. Written consent was taken from each patient. Patient's limb was placed in relaxed position. Room temperature was maintained between $21-23^{\circ} \mathrm{C}$ as any degree rise or fall in temperature can change the results. Electrode gel was applied under the electrode and affix the electrode with adhesive tape to the skin for reduction of electrode impedance. Motor nerve conduction velocity median , ulnar, common peroneal and posterior tibial nerve and sensory nerve conduction velocity median, ulnar and sural nerve were recorded.

Data was entered in Microsoft Excel 2010 and analyzed using Epi info 7.1 and analyzed in terms of mean and SD. T-test for difference of means was used. "P" values equal to or less than 0.05 was considered as significant.

\section{Result}

Mean age of diabetic patients $(51 \pm .4 .8)$ and control group $(48.2 \pm 9.2)$ was comparable $(\mathrm{p}>0.05)$. Twenty six male $(86.7 \%)$ had diabetes. Twenty five patients $(83.3 \%)$ in control group were male. Mean duration of diabetes was $7.0 \pm 3.4$ year.
Table 1: Gender and age wise distibution of case and control group.

\begin{tabular}{|l|l|l|l|}
\hline Characteristicts & Case & Control & P value \\
\cline { 1 - 3 } Age & $51 \pm .4 .8$ & $48.2 \pm 9.2$ & $>0.05$ \\
\hline Male & $\begin{array}{l}26 \\
(86.7 \%)\end{array}$ & $\begin{array}{l}25 \\
(83.3 \%)\end{array}$ & \multirow{2}{*}{$>0.05$} \\
\cline { 1 - 3 } Female & $4(13.3 \%)$ & $5(16.7 \%)$ & \\
\hline
\end{tabular}

Table 2: Comparison of various laboratory parameters case and control group.

\begin{tabular}{|l|l|l|l|}
\hline Parameter & Case & Control & p value \\
\hline HbA1C & $8.1 \pm 1.1$ & $5.5 \pm 0.8$ & $<0.05$ \\
\hline FBS & $136 \pm 13.0$ & $81 \pm 9.7$ & $<0.05$ \\
\hline PPBS & $212 \pm 35.0$ & $130 \pm 9.3$ & $<0.05$ \\
\hline HDL & $25 \pm 3.6$ & $72 \pm 9.5$ & $<0.05$ \\
\hline TG & $161 \pm 23.0$ & $36 \pm 7.5$ & $<0.05$ \\
\hline LDL & $130 \pm 28.0$ & $82 \pm 8.9$ & $<0.05$ \\
\hline $\begin{array}{l}\text { Platelet } \\
\text { count }\end{array}$ & $4.4 \pm 0.5$ & $2.1 \pm 0.4$ & $<0.05$ \\
\hline PT & $13 \pm 1.9$ & $13 \pm 1.9$ & $>0.05$ \\
\hline APTT & $34.8 \pm 2.5$ & $33.5 \pm 2.5$ & $>0.05$ \\
\hline
\end{tabular}

Table 2 shows comparison of various laboratory parameters in subjects of case and control group. HbA1c, fasting blood sugar (FBS), post prandial blood sugar (PPBS) and platelet count were significantly higher in diabetic patients as compared to control group. There was no any significant difference in PT and APTT among two groups. Lipid profile was also significantly altered in diabetic patients. 
Table 3: Motor nerve conduction velocity (MNCV) among case and control group.

\begin{tabular}{|l|l|l|l|}
\hline MNCV & Case & Control & p value \\
\hline Median nerve & $57.3 \pm 3.2$ & $57.0 \pm 3.3$ & $>0.05$ \\
\hline Ulnar nerve & $57.4 \pm 3.1$ & $57.3 \pm 3.2$ & $>0.05$ \\
\hline Common peroneal nerve & $46.0 \pm 2.6$ & $46.6 \pm 2.5$ & $>0.05$ \\
\hline Posterior tibial nerve & $49.4 \pm 3.5$ & $46.9 \pm 8.1$ & $>0.05$ \\
\hline
\end{tabular}

Table 3 shows the MNCV in median, ulnar, common peroneal, and posterior tibial nerves. MNCV of all these nerves were normal in diabetic and non diabetics patients .

Table 4: Sensory nerve conduction velocity (SNCV) among case and control group.

\begin{tabular}{|l|l|l|l|}
\hline SNCV & Case & Control & p value \\
\hline Median nerve & $48.8 \pm 3.9$ & $49.2 \pm 4.0$ & $>0.05$ \\
\hline Ulnar nerve & $58.3 \pm 2.7$ & $54.9 \pm 9.6$ & $>0.05$ \\
\hline Sural nerve & $46.8 \pm 6.8$ & $49.7 \pm 3.9$ & $<0.05$ \\
\hline
\end{tabular}

Results of SNCV of median, ulnar and sural nerve are reported in Table 4. The SNCV of median \& ulnar nerves are normal in control \& cases group. However, sensory nerve conduction in sural nerve of diabetic patients ( $46.8 \pm 6.8)$ was significantly lower as compared to control group $(49.7 \pm 3.9)$. The normal range of sural sensory nerve conduction velocity is $45.5-56.3 \mathrm{~m} / \mathrm{s}$. Eleven subjects $(36.6 \%)$ in cases group were observed with decreased sensory nerve conduction velocity of sural nerve. The mean sensory conduction velocity of sural nerve in these 11 subjects was $38.98 \mathrm{~m} / \mathrm{s}$. They were having subclinical distal sensory peripheral neuropathy.

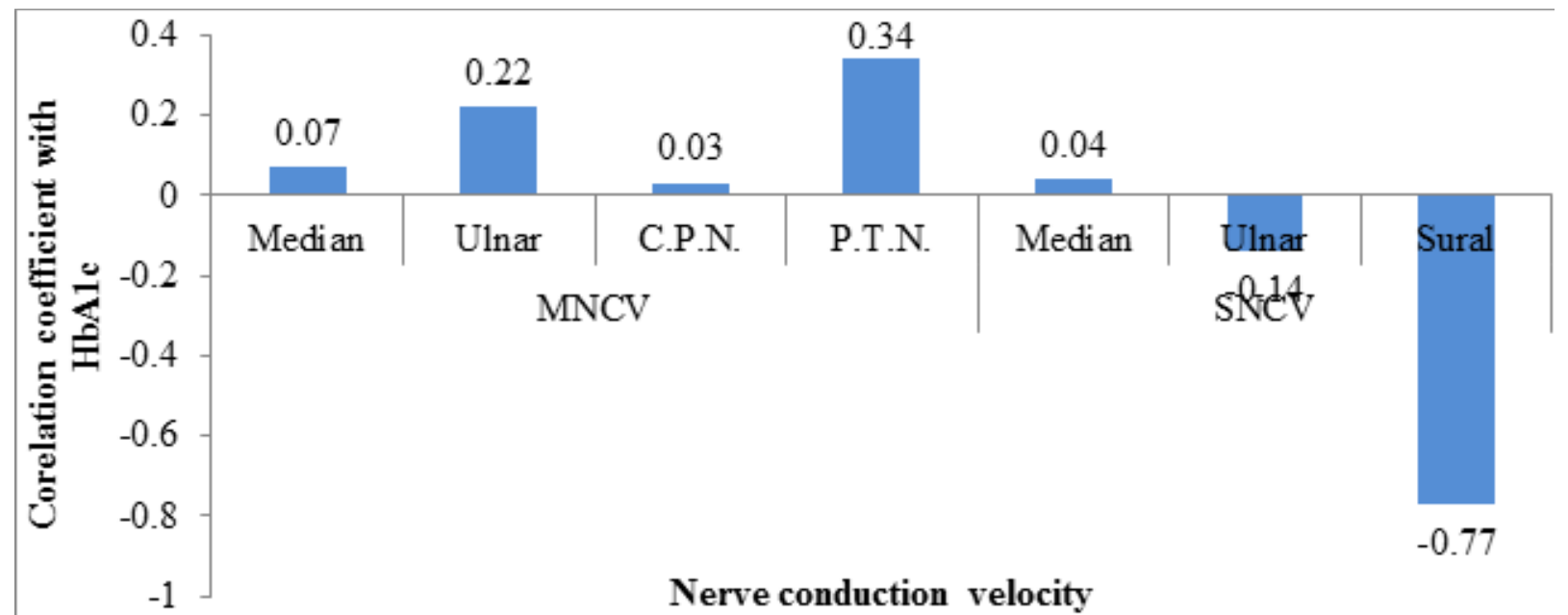

Figure 1: Correlation of $\mathrm{HbA1C}$ with nerve conduction velocity

Correlation between $\mathrm{HbAlc}$ and $\mathrm{NCV}$ in different nerves was summarized in figure 1. Only SNCV of sural nerve was negatively correlated with $\mathrm{HBA}_{1} \mathrm{C}(\mathrm{r}=-0.72)$. 


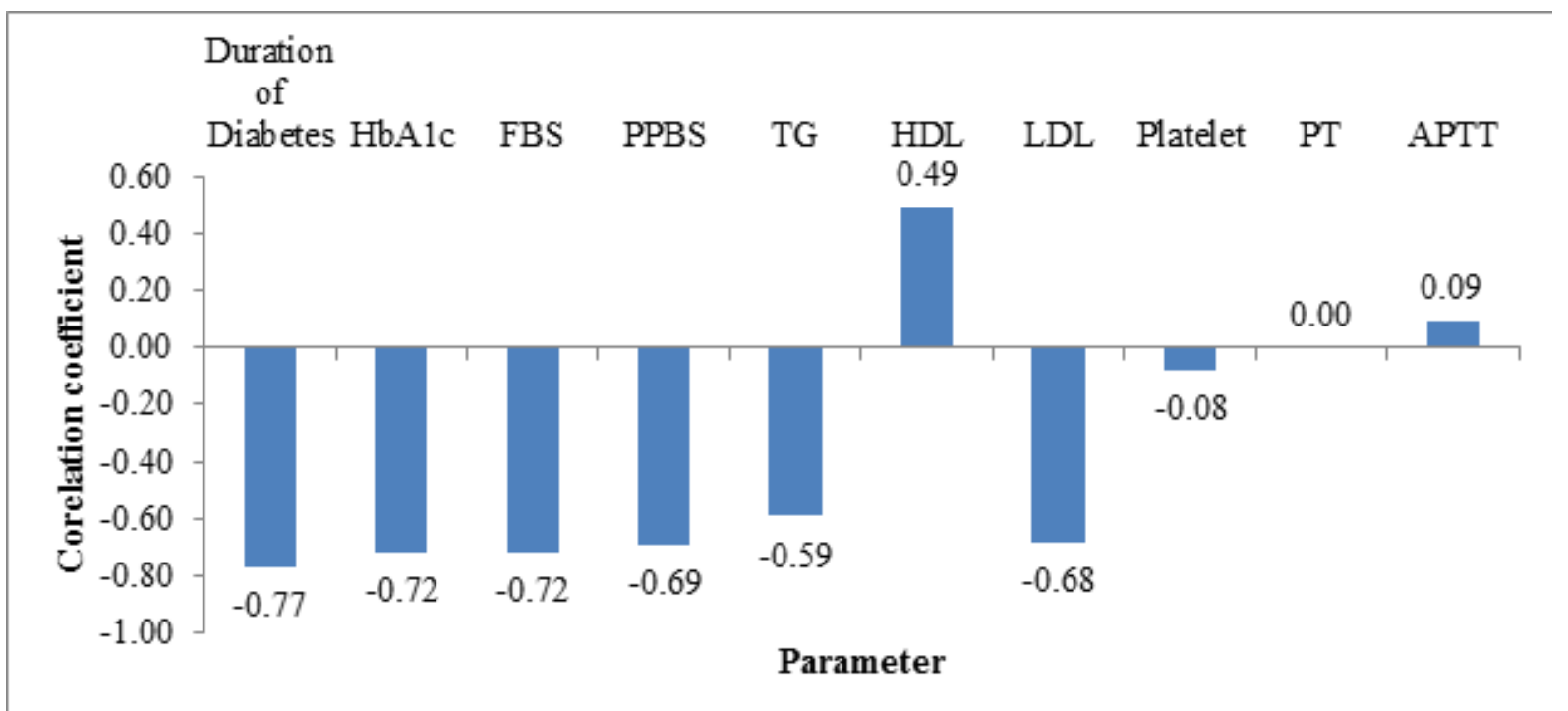

Figure 2: Correlation of SNCV of sural nerve with laboratory parameter and duration of diabetes.

SNCV of sural nerve was negatively correlated with duration of diabetes $(\mathrm{r}=-0.77)$, HBA $\mathrm{C}(\mathrm{r}=-0.72)$, FBS $(\mathrm{r}=-$ 0.72), PPBS ( $\mathrm{r}=-0.69)$, TG ( $\mathrm{r}=-0.59)$ and LDL $(\mathrm{r}=-0.68)$.

\section{Discussion}

In the present study, mean age of diabetic patients was $51 \pm .4 .8$ year. Therefore, the result is applicable only to patients over 50 year age group. Our study group is comparable to other studies with the same age group of subjects. ${ }^{11}$ Most of the subjects $(86.7 \%)$ were male. Other studies also show a higher prevalence of DM in male as compared to females. ${ }^{12}$

In the present study, sensory nerve conduction of sural nerve was signiicantly reduced in diabetic patients as compared to non diabetic patients. Involvement of sural nerve is suggesting that long nerves are commonly affected. ${ }^{13}$ Lower limb is more commonly affected due to length dependent dying back process. We observed that sensory NCS of sural nerve was $f$ inferior with poor glycemic control (higher HbAlc, FBS and PPBS ). Previous study reported that $\mathrm{HbA} 1 \mathrm{c}>6.5 \%$ increased risk for polyneuropathy in DM patients by more than 5-fold. ${ }^{14}$ In the present study, SNCV of sural nerve also showed deterioration with the duration of diabetes. Lee et al.also observed that sural sensory amplitude was significantly associated with polyneuropathy in DM patients. ${ }^{14}$ Oguejiofor et al. reported a higher in patients with a duration of $\mathrm{DM}>15$ years and lower prevalence of neuropathy in those with duration of $\mathrm{DM}<5$ years. ${ }^{15}$ Various studies suggested risk factors for the neuropathy development such as high cholesterol levels, smoking, hypertension, male sex, older age and poor glycaemic control. ${ }^{16,17}$

\section{Conclusion}

The current study shows that diabetic neuropathy is more common in middle and elderly male patients. It was positively relating with duration of diabetes, poor glycemic control and altered lipid profile. Sural nerve was more commonly involved. Nerve conduction velocity testing of sural nerve is useful for early detection of diabetic neuropathy and reduce the burden of complication and to improve the quality of life in diabetics.

Ethical Clearance: Ethical clearance taken from Ethical Review Board, Nalini Chowdhary's neuro center in Hanamkonda, Telangana.

\section{Source of Funding: Self}

\section{Conflict of Interest: Nil}

\section{References}

1. Agarwal S, Lukhmana S, Kahlon N, Malik P, NandiniH. Nerve conduction study in neurologically asymptomatic diabetic patients and correlation with glycosylated hemoglobin and duration of diabetes. National Journal of Physiology, Pharmacy and Pharmacology. 2018;8(11):1533-8.

2. Pradeepa R, Rema M, Vignesh J, Deepa M, Deepa R, Mohan V. Prevalence and risk factors for diabetic neuropathy in an urban south Indian population: the Chennai Urban Rural Epidemiology Study (CURES-55). Diabetic Medicine. 2008 
Apr;25(4):407-12.

3. Franklin GM, Shetterly SM, Cohen JA, Baxter J, Hamman RF. Risk factors for distal symmetric neuropathy in NIDDM: the San Luis Valley Diabetes Study. Diabetes Care. 1994 Oct 1;17(10):1172-7.

4. Claus D, Mustafa C, Vogel W, Herz M, Neundörfer B. Assessment of diabetic neuropathy: Definition of normal and discrimination of abnormal nerve function. Muscle \& Nerve: Official Journal of the American Association of Electrodiagnostic Medicine. 1993 Jul;16(7):757-68.

5. Lamontagne A, Buchthal F. Electrophysiological studies in diabetic neuropathy. Journal of Neurology, Neurosurgery \& Psychiatry. 1970 Aug 1;33(4):442-52.

6. Hendriksen PH, Oey PL, Wieneke GH, Bravenboer B, Van Huffelen AC. Subclinical diabetic polyneuropathy: early detection of involvement of different nerve fibre types. Journal of Neurology, Neurosurgery \& Psychiatry. 1993 May 1;56(5):50914.

7. Kannan MA, Sarva S, Kandadai RM, Paturi VR, Jabeen SA, Borgohain R. Prevalence of neuropathy in patients with impaired glucose tolerance using various electrophysiological tests. Neurology India. 2014 Nov 1;62(6):656.

8. Herman WH, Aubert RE, Engelgau MM, Thompson TJ, Ali MA, Sous ES, Hegazy M, Badran A, Kenny SJ, Gunter EW, Malarcher AM. Diabetes mellitus in Egypt: glycaemic control and microvascular and neuropathic complications. Diabetic Medicine. 1998 Dec;15(12):1045-51.

9. Chatzikosma G, Pafili K, Demetriou M, Vadikolias K, Maltezos E, Papanas N. Evaluation of sural nerve automated nerve conduction study in the diagnosis of peripheral neuropathy in patients with type 2 diabetes mellitus. Archives of medical science: AMS. 2016 Apr 1;12(2):390.

10. Squintani G, Zoppini G, Donato F, Pineschi E, Donini D, Stoico V, Moretto G, Bonora E, Morini
A. Antidromic sensory nerve conduction study of the digital branches of the medial plantar nerve: a novel method to detect early diabetic sensory axonal polyneuropathy. Muscle \& nerve. 2014 Aug;50(2):193-9.

11. Gul S, Dar MA, Ali A, Ashraf A, Qadri S. Prevalence of peripheral neuropathy and pattern of involvement on nerve conduction study in patients of type 2 diabetes mellitus with clinical symptoms of peripheral neuropathy in Kashmiri population: a hospital-based study. Imperial J Interdisciplinary Res. 2017;3(2).

12. American Diabetes Association. 2. Classification and Diagnosis of Diabetes: Standards of Medical Care in Diabetes-2018. Diabetes Care. 2018 1;41(Supplement 1):S13-27.

13. Franssen H. Nerve conduction studies in polyneuropathy: practical physiology and patterns of abnormality. Acta neurologica belgica. 2006 Jun;106(2):73-81.

14. Lee WJ, Jang S, Lee SH, Lee HS. Correlation between the severity of diabetic peripheral polyneuropathy and glycosylated hemoglobin levels: a quantitative study. Annals of rehabilitation medicine. 2016 Apr;40(2):263.

15. Oguejiofor OC, Odenigbo CU, Oguejiofor CB. Evaluation of the effect of duration of diabetes mellitus on peripheral neuropathy using the United Kingdom screening test scoring system, biothesiometry and aesthesiometry. Nigerian journal of clinical practice. 2010;13(3).

16. Harati Y. Diabetic neuropathies: unanswered questions. Neurologic clinics. 2007 Feb 1;25(1):303-17.

17. Fazan VP, de Vasconcelos CA, Valenca MM, Nessler R, Moore KC. Diabetic Peripheral Neuropathies: A Morphometric Overview. International Journal of Morphology. 2010 Mar $1 ; 28(1)$. 